environment there is a big risk from exhaustion due to the body's own heat production during exercise (high humidity makes heat loss by sweating inefficient). That risk would be minimized by the small body size (hence low mass: area ratio) and relatively small muscle mass of African pygmies.

That reasoning must, however, be placed in the context of human size

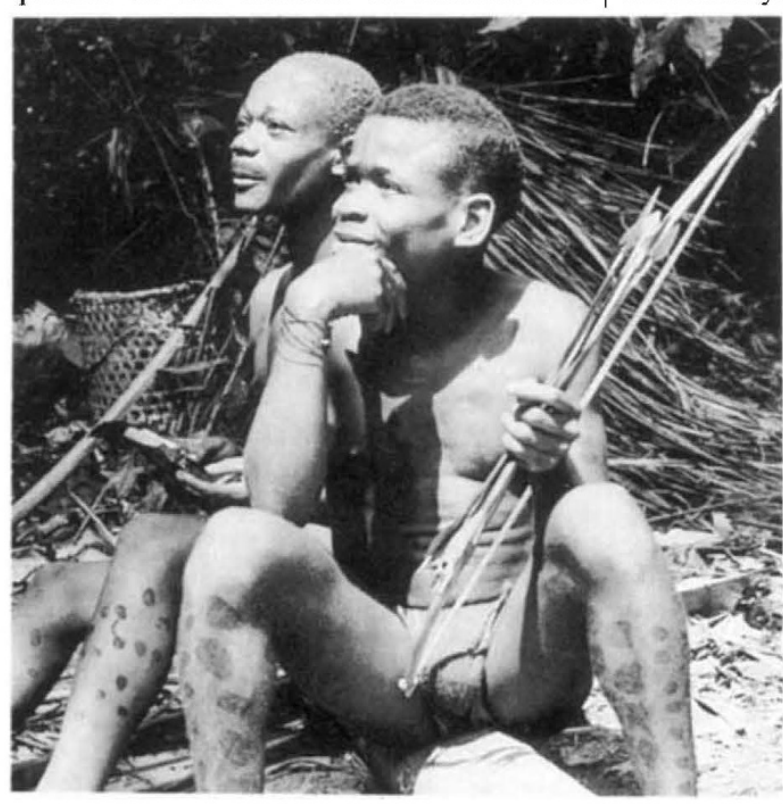

Small world - the Efe pygmies are the world's smallest people, the mean adult height for men and women being $4 \mathrm{ft}$ $8 \mathrm{in}$ and $4 \mathrm{ft} 5 \mathrm{in}$ respectively. (Photo courtesy Robert $\mathrm{C}$. Bailey.)

variation worldwide. Although African pygmies are the smallest of humans, they have many close rivals in certain populations in tropical America, southern Africa and (especially) Asia, the Philippines and New Guinea. Of these populations, the only ones living in hot, humid forests are the Andaman islanders and some Amerindians. In striking contrast to predictions based on Bergmann's rule and heat budgets, human body size consistently declines (rather than increases) with elevation in New Guinea, where the cold, high mountains harbour the smallest people (such as the Goliath Pygmies, oxymoronically named after their homeland on Mount Goliath). The small negritos of the Philippines and the Semang of Malaysia also live in the mountains, not in the steaming lowlands. Kalahari Bushmen are small despite living in a seasonally hot but extremely dry climate. Even the pygmies of equatorial Africa may have evolved at the productive savanna/forest ecotone and been driven into the humid forest only by the Bantu expansion of the past 3,000 years ${ }^{5,6}$. These many paradoxes suggest that there must be evolutionary explanations of pygmy size that are not based solely on thermal considerations.

One such advantage of small size in cool equatorial mountainous areas is in getting through dense vegetation. The lowland rainforest of New Guinea is open enough for even basketball players to walk erect, but the montane forest is a tightly woven maze, as I am reminded every time I bang my head trying to crawl after a little Papuan mountaineer. Turnbull ${ }^{7}$ noted this advantage for forest-dwelling African pygmies as well, and Bailey observed that Efe men spend nine per cent of their waking hours clambering around in trees in search of bees' nests with honey not a safe lifestyle for a sumo wrestler.

Yet this advantage of small size in dense vegetation fails in turn to account for the Kalahari Bushmen, who live in an open habitat. The explanatory factor there may be the desert's low and fluctuating productivity: small people are better able to endure starvation under such conditions. (Recall that the first man to die during Robert Scott's fatal dash to and from the South Pole was big Edgar Evans, starved by months of democratically equal division of dwindling food supplies $^{8}$.) The low productivity (in wild game and agricultural protein) of New Guinea's mountains may similarly favour small statures, and may also contribute to the size of African pygmies; Bailey points out that although they are often portrayed as hunters at home in the forest, African pygmies recognize that they would starve there and actually obtain most of their food by working for nearby farmers ${ }^{5,6}$

Pygmy stature has intrigued scientists for its own sake, just as it intrigued the Pharaoh Nefrikare, Homer and Herodotus. Bailey's work points towards further studies to go beyond that and illuminate the whole issue of what determines human body size.

Jared M. Diamond is in the Department of Physiology, University of California Medical School, Los Angeles, California 90024, USA.

1. Bailey, R. C. Ann. hum. Biol. 18, 113-120 (1991).

2. van de Koppel, J. M. H. \& Hewlett, B. S. in African Pygmies (ed. Cavalli-Sforza, L. L.) 95-101 (Academic New York, 1986)

3. Merimee, T. J. \& Rimoin, D. L. in African Pygmies (ed. Cavalli-Sforza, L. L.) 167-177 (Academic, New York, 1986)

4. Cavalli-Sforza, L. L. in African Pygmies (ed. CavaltiSforza, L. L.) 361-426 (Academic, New York, 1986).

5. Bailey, R. C. \& Peacock, N. R. in Coping with Uncertainty in Food Supply (eds de Garine, I. \& Harrison, G. A.) 88-117 (Clarendon, Oxford, 1988).

6. Bailey, R. C. et al. Am. Anthropologist 91, 59-82 (1989)

7. Turnbuli, C. M. in African Pygmies (ed. Cavalli-Sforza, L L.) 103-123 (Academic, New York, 1986)

8. Scott, R. F. Scott's Last Expedition (Smith. Elder, London, 1913).

\section{Bacterial choirs}

MANY biochemical changes go by means of a closed cycle of reactions. Each cycle takes in reagents, liberates products, and regenerates the intermediates to start itself again. Thus glucose is oxidized in many organisms via the famous Krebs citric-acid cycle. Daedalus now points out that all chemical reactions go with a small change of volume; for a cyclic reaction this change must be cyclic. The tissue supporting a biochemical cycle must expand and contract once per cycle. So it should generate sound: a hum or whistle or ultrasonic signal, depending on how fast the cycle is running.

Living tissue does not obviously whistle while it works. Daedalus explains that any given biochemical cycle operates simultaneously at many sites in each cell or mitochondrion. All the sites have different frequencies and phases, so that their total sound output averages to zero. Daedalus is now synchronizing them.

He argues that a chemical reaction that produces an increase in volume must be slowed by a rise in pressure, but accelerated by a fall. Conversely, a reaction going with a decrease in volume will be encouraged by added pressure and slowed by its reduction. A periodic fluctuation of pressure imposed on a cyclic reaction will therefore tend to entrain that reaction. Its expansion phase will be trapped in the periods of low pressure, while its contraction phase fills the periods of high pressure.

So DREADCO biochemists are now singing to bacteria. They are imposing specific sonic frequencies on bacterial cultures, calculated to match, for example, the Krebs cycle. When the correct frequency and intensity have been found, all the cycles in the culture will come into coherent phase. The bacteria will sing back in close harmony.

Even more intriguing, they should continue to sing when the entraining frequency is switched off. Like a laser, they will maintain their own synchronizing signal, and will function as a coherent free-running oscillator. Thereafter, their frequency will be a perfect monitor of their metabolic rate.

This elegant technique has wide implications. Almost any living tissue, in plants, animals or human beings, could have one of its biochemical cycles entrained and synchronized in this way, and could thereafter sing its reaction rate into a suitable microphone. At last biochemists will have instant, second-tosecond knowledge of the changing metabolic rate of individual tissues. They will sing of their own health, sickness and response to treatment - even, by a note sinking sadly to zero frequency, of their own death.

David Jones 